\title{
2 I 9 Visualization of micro-vasculature using FeCo-core/graphitic-carbon-shell nanocrystals and high-resolution 3D spiral imaging
}

\author{
Jin Hyung Lee*, Masahiro Terashima, Won Seok Seo, Hisanori Kosuge, \\ Sarah Sherlock, Michael McConnell, Dwight Nishimura and Hongjie Daiv
}

Address: Stanford University, Stanford, CA, USA

* Corresponding author

from I th Annual SCMR Scientific Sessions

Los Angeles, CA, USA. I-3 February 2008

Published: 22 October 2008

Journal of Cardiovascular Magnetic Resonance 2008, I0(Suppl I):A388 doi:I0.I I86/I532-429X-I0-SI-A388

This abstract is available from: http://jcmr-online.com/content/I0/SI/A388

(c) 2008 Lee et al; licensee BioMed Central Ltd.

\section{Introduction}

Non-invasive visualization of small vessel structures has been difficult due to insufficient contrast between small vessels and background tissue, and limited spatial resolution of MRI. Here, we present a method to non-invasively visualize small vascular structures in-vivo, in live animals using novel contrast agents combined with fast, high resolution image encoding methods.

\section{Purpose}

To evaluate the use of 1) the FeCo-Core/Graphitic-Carbon-Shell nanocrystal contrast agent [1] and 2) the high resolution encoding enabled by $3 \mathrm{D}$ spiral acquisition and small surface coils for the visualization of microvasculature in-vivo.

\section{Methods}

Normal and stenosis induced white rabbits with body weight of $\sim 4 \mathrm{~kg}$ were first catheterized in the ear vein. Through the catheter, $9.6 \mathrm{cc}$ of $5 \mathrm{mM}$ concentration FeCo nanocrystal contrast agent was injected followed by $1 \mathrm{cc}$ of saline injection. Immediately before and after the injection, a small volume covered by a 1 inch custom made surface coil was imaged using spectral-spatial excitation and 3D spiral readout. The spatial resolution was $78 \times 78$ $\times 500 \mathrm{um}^{3}$ with volume coverage of $4 \times 4 \times 1 \mathrm{~cm}^{3}$. The scan time was 2 min $40 \mathrm{sec}$ for a single volume and the scan was repeated 9 times over 24 min to improve SNR. A whole body volume scan using a fat-saturated 3D SPGR sequence was also performed using a standard GE head coil 1 hour before and after the injection. All the experiments were conducted using a GE 1.5 T EXCITE whole body system with a maximum gradient of $40 \mathrm{mT} / \mathrm{m}$ and maximum slew rate of $150 \mathrm{~T} / \mathrm{m} / \mathrm{s}$.

\section{Results}

The FeCo nanocrystal contrast agent's ability to produce high enhancement with $0.2 \mathrm{mM}$ blood concentration which is $10 \%$ of Gd (Magnevist) dosage is demonstrated in Fig. 1. Enhancement factor of 9 is achieved (Figure 1b, c) as expected from the relaxivity parameters (Figure 1a). The aortic stenosis can also be clearly observed in Fig. 1b. With this strong enhancement and high resolution acquisition, small vessels down to $78 \mathrm{um}$ in diameter were successfully visualized in-vivo (Figure. 2b).

\section{Conclusion}

The FeCo contrast agent provides several advantages for high resolution vessel imaging; strong relaxivity, relatively long circulation time compared to conventional Gd based contrast agent, and small nano-scale size. These properties allow sufficient contrast in the small vessels for a long enough time to acquire high resolution images. The high resolution 3D spiral imaging technique combined with this FeCo contrast agent demonstrates great potential to visualize microvasculature in-vivo. 

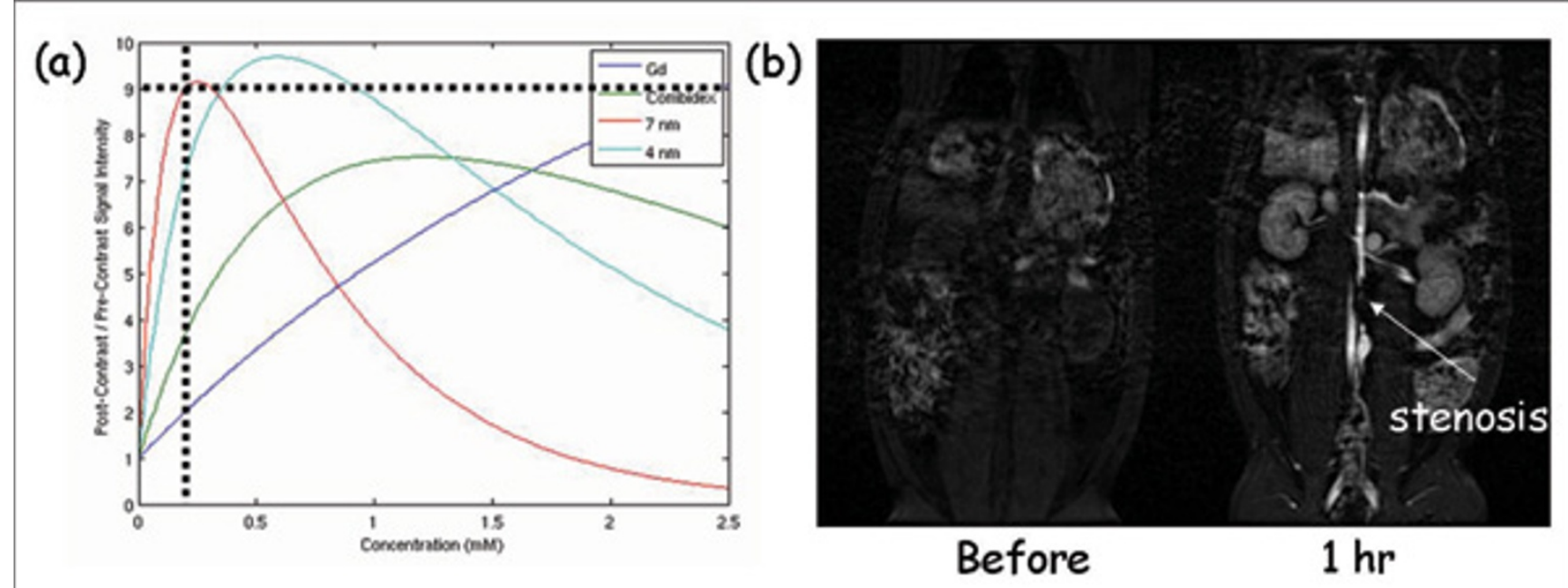

\begin{tabular}{c|c|c|c}
\hline Mean Signal & Before & $1 \mathrm{hr}$ & Ratio \\
\hline Aorta & 242 & 2182 & 9.0 \\
\hline Muscle & 305 & 315 & 1.0 \\
\hline
\end{tabular}

Figure I

The relaxivity parameters of various contrast agents indicate that with the SPGR acquisition, $0.2 \mathrm{mM}$ blood concentration can produce 9 fold signal enhancement with the FeCo nanocrystal based contrast agent (a). The predictions are confirmed in (b), (c) and (b) also shows a nice depiction of the aortic stenosis.

In this paper, we present a method to non-invasively visualize small vascular structures ( $78 \mathrm{um}$ ) in-vivo, in live animals using novel FeCo-Core/Graphitic-Carbon-Shell nanocrystal contrast agents combined with fast, high resolution 3D spiral encoding methods.

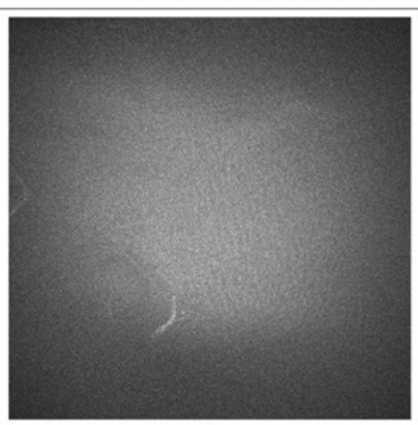

(a)

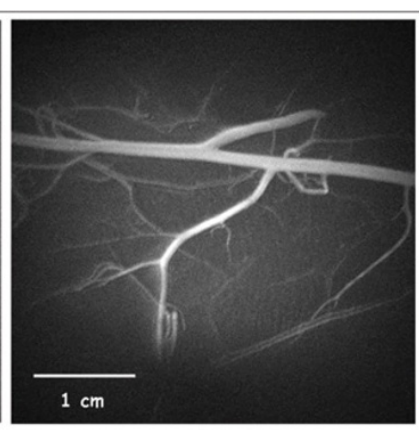

(b)

\section{Figure 2}

Maximal intensity projection (MIP) of the vessel images in the rabbit leg (a) before contrast injection, and (b) immediately after contrast injection.

\section{References}

I. Seo WS, et al.: Nat Mater 2006, 5(I 2):97|-6.

Publish with Bio Med Central and every scientist can read your work free of charge

"BioMed Central will be the most significant development for disseminating the results of biomedical research in our lifetime."

Sir Paul Nurse, Cancer Research UK

Your research papers will be:

- available free of charge to the entire biomedical community

- peer reviewed and published immediately upon acceptance

- cited in PubMed and archived on PubMed Central

- yours - you keep the copyright
BioMedcentral 